\title{
PEMBERDAYAAN KELOMPOK WANITA TANI DALAM PEMANFAATAN PEKARANGAN DI DESA LAPRI KABUPATEN NUNUKAN
}

\section{Empowerment of Women Farmer Group in the Use of Yard in Lapri Village Regency of Nunukan}

\author{
Nia Kurniasih Suryana ${ }^{1^{*}}$, Hendris ${ }^{2}$ \\ ${ }^{1.2}$ Fakultas Pertanian \\ Universitas Borneo Tarakan, Jalan Amal Lama, Tarakan \\ * Penulis Korespodensi : zylnia@gmail.com
}

\begin{abstract}
ABSTRAK
Tingkat kemandirian pangan di wilayah perbatasan Indonesia-Malaysia cukup rendah, hal ini terlihat dari ketersediaan bahan pangan lebih banyak dipasok dari Malaysia. Potensi alam yang dimiliki masyarakat Sebatik cukup berlimpah termasuk lahan pekarangan yang bisa dimanfaatkan untuk dapat menyediakan pangan secara mandiri. Tempat pelaksanaan pengabdian kepada masyarakat di kelompok wanita tani "Bunga Harapan” dan "Semangat Baru” selama 3 bulan. Tujuan dari kegiatan pengabdian kepada masyarakat ini adalah meningkatkan pengetahuan dan keterampilan kelompok wanita tani dalam memanfaatkan pekarangan dengan budidaya system vertikultur. Target dan luaran yang diharapkan dari Kelompok kelompok wanita tani “ Bunga Harapan” dan "Semangat Baru” ini adalah merubah perilaku yang meliputi pengetahuan, keterampilan dan sikap masyarakat melalui penyuluhan, pelatihan budidaya tanaman hortikultur dengan system vertikultur.
\end{abstract}

Kata Kunci : Lahan, Pekarangan, Kelompok Tani, Wanita, Perbatasan

\section{ABSTRACT}

The level of food independence in the border area of Indonesia-Malaysia is quite low, it is seen from the availability of more foodstuffs supplied from Malaysia. The natural potential owned by the Sebatik community is quite abundant including yard that can be used to provide food independently. Place of devotion to the community in the Peasant Women group "Bunga Harapan" and "New Spirit" for 3 months. The purpose of this community service is to increase the knowledge and skills of the farmer's group in the use of the yard with the cultivation of the verticulture system. The Target and exterior expected of the group of women farmers "Bunga Harapan" and "new spirit" are changing behaviors that include knowledge, skills and attitude of society through counseling, horticultured cultivation training With a planting system.

Keywords: Land, Yard, Farmer Group, Women, Border

\section{PENDAHULUAN}

Pekarangan dapat dimanfaatkan untuk menanam berbagai jenis tanaman seperti tanaman pengganti makanan pokok, hias, obat dan lain-lain. Penataan tanaman ini dipekarangan dapat dilakukan sedemikian rupa.

Kesegaran makanan yang tersedia seperti sayur dan buah mengalami degradasi kualitas dalam perjalanannya. hal yang bisa dilakukan adalah memperdekat akses terhadap bahan makanan tersebut. Dengan demikian kebutuhan gizi keluarga dapat dipenuhi secara berkesinambungan sekaligus meningkatkan keterampilan keluarga tani dalam budidaya tanaman (Suedi,dkk, 2013). Disamping itu juga menanam sayuran di pekarangan dapat 
melestarikan lingkungan karena oksigen yang dihasilkan tanaman tersebut. Permasalahan di wilayah perbatasan adalah ketersediaan bahan pangan terutama sayuran. Desa Lapri Kecamatan Sebatik Tengah Kabupaten Nunukan merupakan salah satu desa yang berada di perbatasan Indonesia-Malaysia. Mata pencaharian penduduknya lebih banyak di sector pertanian dan perkebunan. Komoditi yang banyak diusahakan adalah padi, sawit dan kakao. Ketersediaan bahan pangan jenis hortikultura terutama sayuran justru lebih banyak dipasok dari Negara tetangga yaitu Malaysia. Dengan demikian ada beberapa prioritas kebutuhan terutama di wilayah perbatasan secara umum yang meliputi; 1) Penguatan kelembagaan melalui pembentukan kelompok tani; 2) Peningkatan SDM melalui pelatihan pembibitan tanaman pangan dan hortikultura; 3) Pemberdayaan lahan pekarangan; 4) Pengadaan atau inisiasi lahan budidaya; 5) Kegiatan Budidaya di lahan demplot.

Pemanfaatan pekarangan juga memberikan nilai positif pada penekanan pengeluaran biaya rumah tangga. Kegiatan pemberdayaan kelompok wanita tani melalui optimalisasi pemanfaatan pekarangan diharapkan dapat menyediakan pangan secara mandiri dan meningkatkan kesejahteraan (Syarief.dkk, 2014).

\section{METODE}

Berdasarkan permasalahan yang dihadapi oleh masyarakat Desa Lapri Kecamatan Sebatik Tengah Kabupaten Nunukan maka ada beberapa solusi yang ditawarkan yaitu :

\section{Penyuluhan}

Penyuluhan yang diberikan kepada kelompok wanita tani di Desa Lapri Kabupaten Nunukan bertujuan untuk meningkatkan pengetahuan tentang cara membuat media tanam, membuat pupuk organik serta cara budidaya hortikultur dengan system vertikultur . Metode penyuluhan dilakukan secara kelompok dengan melakukan pertemuan, serta diskusi. Media yang dipergunakan media terproyeksi berupa gambar dan atau tulisan lewat slide. Materi yang disampaikan dalam penyuluhan meliputi :

1) Pembuatan Media Vertikultur

2) Pembuatan Pupuk Organik

3) Cara Budidaya Hortikultur dengan system vertikultur

\section{Pelatihan}

Pelatihan merupakan proses pembelajaran yang memungkinkan seseorang dapat melakukan suatu pekerjaan sesuai dengan standar.

Pelatihan yang dilakukan untuk kelompok wanita tani di Desa Lapri Kabupaten Nunukan dengan praktek secara langsung cara budidaya tanaman hortikultur dengan system vertikultur. Pelatihan yang diberikan meliputi :

1) Praktek cara membuat Media Vertikultur

2) Praktek cara menanam tanaman hortikultur dengan system vertikultur

\section{Pendampingan}

Kegiatan pendampingan dimaksudkan mendampingi sekaligus memantau perkembangan usahanya dari apa yang telah diperoleh dalam kegiatan Program Pengabdian pada Masyarakat ini. Pendampingan dilakukan dengan tujuan kegiatan yang ada tetap berjalan dengan hasil akhirnya peningkatan pendapatan dan kesejahteraan masyarakat perbatasan.

Partisipasi mitra dalam pelaksanaan kegiatan ini dimulai dari perencanaan sampai pelaksanaan kegiatan. Materi dalam penyuluhan dan pelatihan berdasarkan pada kebutuhan. 


\section{HASIL DAN PEMBAHASAN}

\subsection{Penyuluhan Pemanfaatan}

\section{Pekarangan}

Penyuluhan dilaksanakan dengan tujuan agar sasaran dapat meningkatkan pengetahuannya tentang bagaimana memanfaatkan lahan pekarangan supaya lebih produktif dan mengetahui bagaimana cara budidaya tanaman dengan memanfaatkan lahan yang sempit dengan sistem vertikultur.

Penyuluhan dilaksanakan tanggal 20 Juli 2018 bertempat di Kantor Desa Lapri. Sasaran kegiatan penyuluhan ini adalah anggota Kelompok Wanita Tani Bunga Harapan dan Kelompok Wanita Tani Semangat Baru sebanyak 20 orang.

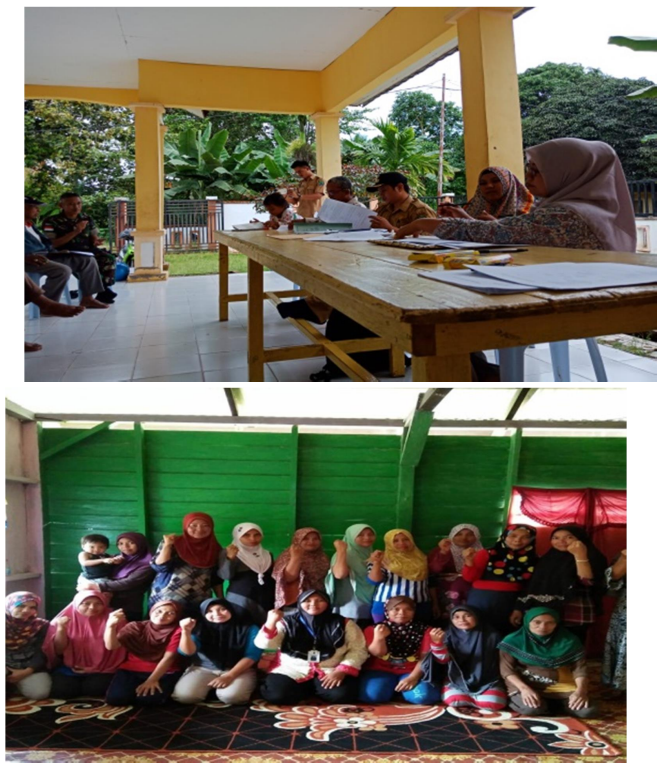

Gambar 1. Pelaksanaan Penyuluhan Tentang Pemanfaatan Pekarangan

Materi yang disampaikan meliputi pengertian tentang pekarangan, manfaat serta model pemanfaatan pekarangan.

Pekarangan dapat dimanfaatkan sebagai warung hidup, apotek hidup, lumbung hidup maupun bank hidup. Sebagai apotek hidup, dimana pekarangan ditanami berbagai jenis tanaman yang dapat dijadikan obat keluarga (TOGA). Model atau perencanaan pemanfaatan pekarangan harus memperhatikan hal-hal sebagai berikut :

a. Pengolahan lahan.

b. Menentukan Jenis Tanaman.

c. Menentukan Tata Letak Tanaman.

d. Pemeliharaan baik untuk lahan maupun tanaman merupakan hal yang harus selalu diperhatikan. Indikator keberhasilan kegiatan pengabdian ini adalah rata-rata $90 \%$ dari peserta kegiatan telah mengetahui dan memahami tentang pemanfaatan pekarangan.

Tabel 1. Pemahaman Sasaran Setelah Dilakukan Penyuluhan

\begin{tabular}{|c|c|c|c|c|c|}
\hline \multirow{2}{*}{ No } & \multicolumn{2}{|c|}{ Pernyataan } & \multicolumn{2}{|c|}{ Ya } & \multicolumn{2}{c|}{ Tidak } \\
\cline { 2 - 6 } & Jumlah & Presentase & Jumlah & Presentae \\
\hline 1 & $\begin{array}{l}\text { Setelah penyuluhan mengerti } \\
\text { tentang pengertian pemanfaatan } \\
\text { pekarangan }\end{array}$ & 18 & $90 \%$ & 2 & $10 \%$ \\
\hline 2 & $\begin{array}{l}\text { Setelah penyuluhan memahami } \\
\text { tujuan dari pemanfaatan } \\
\text { pekarangan }\end{array}$ & 16 & $80 \%$ & 4 & $20 \%$ \\
\hline 3 & $\begin{array}{l}\text { Setelah penyuluhan mengetahui } \\
\text { manfaat dan fungsi dari pekarangan }\end{array}$ & 18 & $90 \%$ & 2 & $10 \%$ \\
\hline 4 & $\begin{array}{l}\text { Setelah penyuluhan mengetahui } \\
\text { tentang perencanaan pemanfaatan } \\
\text { pekarangan }\end{array}$ & 18 & $90 \%$ & 2 & $10 \%$ \\
\hline 5 & $\begin{array}{l}\text { Setelah penyuluhan mengetahui } \\
\text { tentang tanaman yang bisa } \\
\text { dibudidayakan di pekarangan }\end{array}$ & 20 & $100 \%$ & 0 & $10 \%$ \\
\hline
\end{tabular}

Sumber: Pengolahan Data Primer, 2018

\subsection{Pelatihan Budidaya Vertikultur}

Pelatihan dilaksanakan bertujuan untuk meningkatkan keterampilan sasaran. Kegiatan pelatihan dilaksanakan pada tanggal 18 Agustus 2018 bertempat di halaman Kantor Desa Lapri. Materi yang disampaikan mengenai cara budidaya vertikultur yang dapat diaplikasikan di pekarangan rumah.

Sistem pemanfaatan pekarangan dengan teknik budidaya vertikultur adalah sistem budidaya yang dilakukan secara vertikal atau bertingkat.Sistem ini sangat cocok diterapkan di wilayah perkotaan seperti wilayah tempat dilakukan penelitian ini yang memiliki lahan pekarangan yang sempit. Pada sistem ini budidaya dilakukan untuk mengoptimalkan lahan dengan memanfaatkan media yang ditempatkan 
secara vertikal, selain itupola ini juga menghemat dalam penggunaan pupuk dan air. Vertikultur sangat bermanfaat untuk memaksimalkan hasil karena jumlah tanaman yang dapat dibudidayakan menjadi lebih banyak dan bisa beragam jenis bila diinginkan.

Teknik budidaya vertikultur dalam penelitian ini menggunakan 3 macam berdasarkan tata letaknya, yaitu vertikultur bertingkat, vertikultur berdiri dan vertikultur bergantung. Kesemua jenis tersebut mudah untuk dilakukan oleh anggota keluarga dan sangat cocok untuk tanaman hortikultur terutama sayuran dan tanaman obat. Media yang digunakan untuk budidaya vertikultur ini berasal dari paralon dan botol plastik bekas.

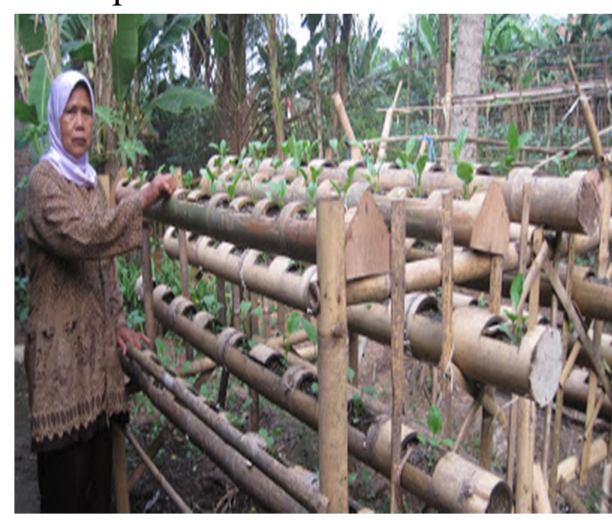

Gambar 2. Media dan Sistem Vertikultur secara Bertingkat

\section{Vertikultur Berdiri}

Disebut vertikultur berdiri karena wadah yang digunakan untuk menanam sayuran dalam keadaan berdiri di atas tanah. Wadah yang digunakan maupun cara pemeliharaannya sama dengan penanaman di pot. Selain pipa PVC, teknik bertanam ini juga bisa diterapkan pada bambu berdiameter besar (bambu betung) dengan terlebih dahulu membuang pembatas ruasnya.
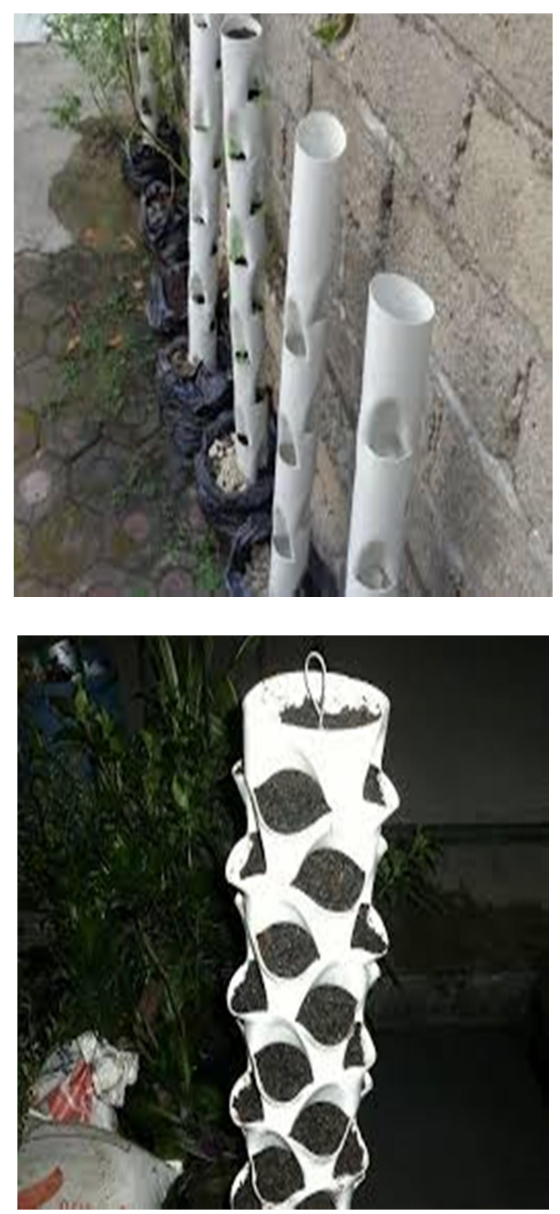

Gambar 3. Media dan Sistem Vertikultur secara Berdiri

\section{Vertikultur Bergantung}

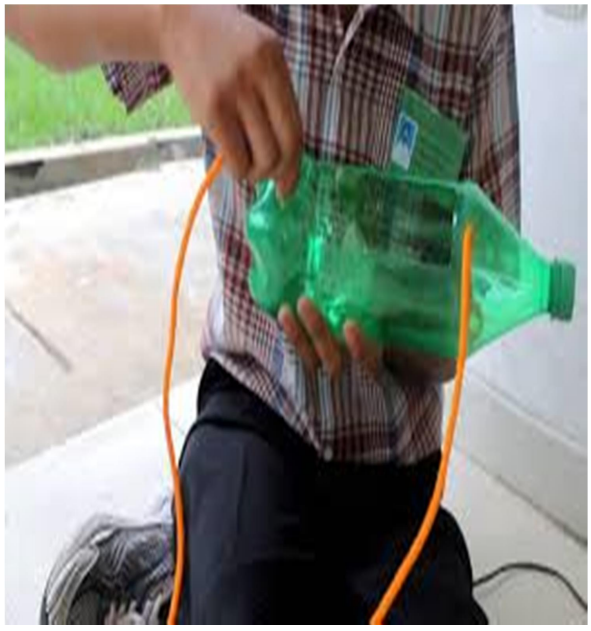




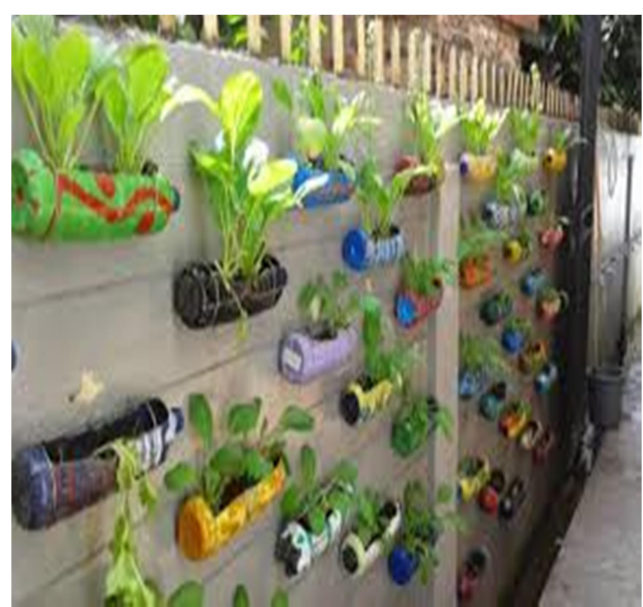

Gambar 4. Media dan Sistem Vertikultur Secara Bergantung

Indikator keberhasilan kegiatan pengabdian ini adalah rata-rata $95 \%$ dari peserta kegiatan telah mampu membuat budidaya sistem vertikultur.

Tabel 2. Keterampilan Sasaran Setelah Dilakukan Pelatihan

\begin{tabular}{|c|c|c|c|c|c|}
\hline \multirow[b]{2}{*}{ No } & \multirow[b]{2}{*}{ Pernyataan } & \multicolumn{2}{|c|}{ Ya } & \multicolumn{2}{|c|}{ Tidak } \\
\hline & & Jumlah & Presentase & Jumlah & Presentae \\
\hline 1 & $\begin{array}{l}\text { Setelah pelatihan dapat membuat } \\
\text { media tanam (komposisi tanah dan } \\
\text { pupuk) }\end{array}$ & 20 & $100 \%$ & 0 & $0 \%$ \\
\hline 2 & $\begin{array}{l}\text { Setelah pelatihan dapat membuat } \\
\text { media vertikultur secata bertingkat }\end{array}$ & 19 & $95 \%$ & 1 & $5 \%$ \\
\hline 3 & $\begin{array}{l}\text { Setelah pelatihan dapat membuat } \\
\text { media vertikultur secara berdiri }\end{array}$ & 19 & $95 \%$ & 1 & $5 \%$ \\
\hline 4 & $\begin{array}{l}\text { Setelah pelatihan dapat membuat } \\
\text { media vertikultur secara bergantung }\end{array}$ & 20 & $100 \%$ & 0 & $0 \%$ \\
\hline 5 & $\begin{array}{l}\text { Setelah pelatihan dapat melakukan } \\
\text { budidaya tanaman hortikultur }\end{array}$ & 20 & $100 \%$ & 0 & $0 \%$ \\
\hline
\end{tabular}

Sumber: Pengolahan Data Primer, 2018

\subsection{Pendampingan}

Pendampingan dilakukan bersama penyuluh yang menjadi pembina kelompok Wanita Tani Bunga harapan dan kelompok Wanita Tani Semangat Baru. Pendampingan menggunakan metode secara langsung dan tidak langsung. Pendampingan secara langsung dengan cara individu melalui kunjungan rumah dan kunjungan ke lokasi usaha dan secara kelompok melalui pertemuan dan diskusi, sementara pendampingan secara tidak langsung dilakukan dengan melalui media seperti telepon, dan media social.

\section{PENUTUP}

Berdasarkan hasil kegiatan yang telah dilaksanakan disimpulkan bahwa tim pengabdi telah: Meningkatkan pengetahuan dan ketrampilan anggota Kelompok Tani Bunga harapan dan kelompok Wanita Tani Semangat Baru dalam memanfaatkan pekarangan untuk budidaya tanaman hortikultur. Meningkatkan pengetahuan dan ketrampilan anggota Kelompok Tani Bunga harapan dan kelompok Wanita Tani Semangat Baru dalam melakukan budidaya secara vertikultur.

\section{DAFTAR RUJUKAN}

Amanah.S. 2007. Makna Penyuluhan dan Transformasi Prilaku Manusia. Jurnal Penyuluhan. Desember 2007 Vol 3 No 1, ISSN : 1858.2664.

Badan Pusat Statistik. 2014. Tarakan Dalam Angka Tahun 2014. Tarakan.

Suaedi,Nurhilal,Musindar. 2013. Peran Wanita Tani dalam Pemanfaatan Pekarangan untuk Tanaman Pangan. Jurnal Perbal. Fakultas Pertanian. Universitas Cokroaminoto. Palopo.Volume 2 No 3 . 3 Oktober 2013.

Syarief, Sumardjo, Fatchia. 2014. Kajian Model Pemberdayaan Ketahanan Pangan di Wilayah Perbatasan Antar Negara(Assessment of Food Security Empowerment Modelin Inter-State Border) Jurnal Ilmu Pertanian Indonesia (JIPI), April 2014Vol. 19 (1): $\quad 913 \quad$ ISSN $0853 \quad-4217$. 
